\title{
O PLANEJAMENTO DA ATIVIDADE ECONÔMICA MINERÁRIA E O DESENVOLVIMENTO SUSTENTÁVEL
}

\section{RESUMO:}

Edson José de Souza Júnior*

O artigo analisa a atividade de planejamento econômico da atividade minerária como dever do Estado. Apresenta a Compensação Financeira pela Exploração dos Recursos Minerais (CFEM), seu marco legal, sua natureza jurídica e destinação dos recursos recebidos pelas entidades estatais a partir dos respectivos repasses. A partir de revisão bibliográfica e análise dos documentos primários citados, objetiva propor a criação de um fundo especial para gerir esses recursos, promovendo o desenvolvimento sustentável da atividade mineraria e a realização do direito fundamental à boa administração. Utiliza método dialético.

PALAVRAS CHAVES: Mineração; Compensação Financeira pela exploração dos Recursos Minerais CFEM; Sustentabilidade social econômica e ambiental; Planejamento e desenvolvimento sustentável; Criação de Fundo;

\section{Planning of mining economic activity and sustainable development}

\begin{abstract}
:
The article analyzes the activity of economic planning of mining activity as a duty of the State. It presents the Financial Compensation for the Exploration of Mineral Resources (CFEM), its legal framework, its legal nature and allocation of resources received by state entities from the respective onlendings. Based on bibliographic review and analysis of the primary documents cited, it aims to propose the creation of a special fund to manage these resources, promoting the sustainable development of mining activity and the realization fundamental right to good administration. It uses dialectical method.

KEYWORDS: Mining; Financial Compensation for the exploitation of Mineral Resources CFEM; Social economic and environmental sustainability; Planning and sustainable development; Background Creation;
\end{abstract}

\section{INTRODUÇÃO}

O presente artigo foi desenvolvido da necessidade de verificar que a atividade de planejamento econômico como dever do Estado após a promulgação do atual texto constitucional, além de verificar a necessidade de realização do direito fundamental à boa administração, conjugada com a necessidade de proporcional um desenvolvimento sustentável.

Sem cair em lugar comum, tem-se que a atividade mineraria é de extrema importância para continuidade da espécie humana, estando presente desde a mais simples das atividades e até as mais complexas. Assim, desde a atividade da agricultura, com a utilização de adubos e minerais para correção do solo até a indústria de alta tecnologia, com a fabricação

\footnotetext{
* Professor universitário e advogado. Doutor em Educação/ PUC-GO. Doutorando em Direito/Estácio de Sá. Mestre em Educação e em Direito Agrário/UFG. Graduado pela UFG. E-mail: ejsj@bol.com.br
} 
de nano chips, carece da atividade minerária como subjacente e como suporte do desenvolvimento humano. Enfim, somos todos dependentes da exploração dos minerais.

Mas qual desenvolvimento espera-se obter a partir desta imprescindível atividade humana? Essa preocupação e como alcançar o desenvolvimento sustentável da atividade minerária é o ponto de partida de análise de presente artigo, posto que uma das resposta é formatada a partir do recebimento da Compensação Financeira pela exploração dos Recursos Minerais (CFEM), que sustentam ou deveriam sustentar políticas públicas econômicas, sociais e ambientais em vista da ocorrência de possíveis intercorrências que tornem inviável a exploração, ou diante da inevitável exaustão do recurso mineral que podem comprometer nas receitas locais até então incrementadas pela atividade mineraria.

Assim, busca-se compreender inicialmente a atividade de planejamento estatal, especialmente voltado para atividade mineraria. Após, busca-se compreender o conceito, natureza jurídica e destinação dos recursos recebidos pelas entidades estatais a partir dos repasses da Compensação Financeira dos Recursos Minerais (CFEM), e, de forma propositiva, apresenta uma alternativa de desenvolver uma política pública setorial que visa minorar os impactos da atividade mineraria com a criação de um fundo especial para gerir esses recursos, promovendo o desenvolvimento sustentável da atividade mineraria e a realização do direito fundamental à boa administração.

Trata-se de ensaio confeccionado a partir de revisão bibliográfica e utilizou como aporte teórico as análises proporcionadas por Castro Júnior e Silva (2018); Lott (2019); Lucas (2015); Martins e Tomelin (2014); Silva (2014; Silva (2017); dentre outros.

Buscando inovar, buscou-se dialogar com a leitura de autores que não são tão associados diretamente à discussão da questão minerária, tais como Adri (2010); Freitas (2014); Muñoz (2012), o que denota o caráter interdisciplinar, numa simbiose de grande valor enunciativo e utilidade para todos os que se dedicam ao desenvolvimento regional, aliado desenvolvimento econômico e social, aliada a proteção ambiental.

Afinal, concluiu-se pode haver um incremento para o desenvolvimento local, regional e nacional, caso haja a aplicação adequada dos recursos arrecadam com a CFEM, no que a criação de fundos municipais, estaduais e federal que visem elidir os impactos sociais, econômicos e ambientais da atividade mineraria, proporcionando um desenvolvimento sustentável, ainda mais quando consideramos que as riquezas minerais são bens da União e somente deve ser explorados na conveniência e no proveito do povo brasileiro.

\section{O PLANEJAMENTO DA EXPLORAÇÃO MINERÁRIA COMO ATIVIDADE OBRIGATÓRIA DE INTERVENÇÃO NO DOMÍNIO ECONÔMICO}

Os artigos 170 e seguintes do texto constitucional vigente, deixa evidente que não nos filiamos ao modelo de economia planificada, mas sim a um sistema capitalista, que pretende assegurar existência digna, com a observância dos postulados da livre iniciativa e da valorização do trabalho.

Esses postulados que fundamentam todo o modelo de nosso sistema interventivo, implicando em conduzir os modos de raciocínio e de argumentação relativamente às normas, devendo ocorrer, justamente por isso, uma compatibilização da interpretação de todas as normas (princípios e regras), com o prestígio do trabalho e da liberdade de iniciativa.

É inquestionável a imperativa a necessidade de uma atuação mais proativa por parte do Estado em possibilitar o gozo de facilidades para o desenvolvimento econômico das instituições, mas, ao mesmo tempo, submetê-las às limitações estatais, para que a atuação seja tida como legítima e não nociva, ainda mais quando se explora um bem pertencente à União, qual seja, os recursos minerais. 
Daí a importância do planejamento da atividade mineraria como dever do Estado. Mas só um planejamento holístico da atividade mineraria vai permitir a análise do custo de oportunidade da exploração da atividade. Silva $(2017$, p. 2) estabelece que:

A exploração dos recursos minerais pode, ao invés, de estimular setores da econômica, produzir efeito enclave. Este efeito torna-se um obstáculo a diversificação produtiva, na medida em que a produção, em sua forma mais bruta, [e destinado ao exterior, em busca de lugares mais lucrativos e atraentes para sua agregação de valor. Ao proporcionar o escoamento da riqueza ao mercado internacional, afora a apequenada contribuição a economia nacional, entradas massivas de moeda estrangeira sobrevalorizam a moeda local, dificultando ainda mais o crescimento de outros setores. Com isso, a atividade extrativa passa a ser referência, prejudicando, portanto, a economia pátria e trazendo o receito da desidustrialização ou reprimarização.

Importante destacar que este planejamento deverá estar envolvido com questões éticas, para além das questões econômicas, para preservar o meio ambiente, para resguardar a mão de obra empregada na atividade minerária após a exaustão do recurso ou paralisação das atividades, bem como possibilitar a realização de outros investimentos econômicos alternativos à atividade minerária, que permitam a sustentabilidade econômica da comunidade atingida pela atividade da mineração.

O texto constitucional nos dá algumas pistas quando determinar que os entes estatais exerçam funções de fiscalização, incentivo e planejamento, sendo que o último deve ser determinante para o setor público e indicativo para o setor privado. Porém, na prática, essas funções [fiscalização, incentivo e planejamento] não são incumbência simples e muitas vezes são negligenciadas pelo Estado.

Explicitando que o cumprimento dessas funções reclama não só modificação estrutural, mas, sobretudo, de atitude e mentalidade, Adri (2010, p. 57) leciona que:

\begin{abstract}
A tarefa de redesenhar o "novo" Estado, atribuindo-lhe o papel de precursor do bemestar social, exige muito mais do que a revisão de organogramas, do reagrupamento ou extinção de departamentos, da releitura de manuais de conduta, da "desregulamentação" e da "desburocratização" de normas e procedimentos. Trata-se de tudo isso somado à difícil tarefa de reengenharia institucional, que requer anseios políticos e sociais destinados a conhecer e modificar hábitos, comportamentos e mentalidades.
\end{abstract}

Todo o engajamento estatal na trilha de uma Constituição Econômica e Social possibilita um Estado "planejado, previsível e transparente, que confere à sociedade regida a segurança jurídica esperada numa República Federativa que se diz um Estado Democrático de Direito" (ADRI, 2010, p. 57).

Pelos comandos constitucionais percebe-se que a intervenção limitada do Estado na atividade econômica uma determinação constitucional. Perseguindo-se sempre, por meio dela, será assegurada a existência digna, a justiça social e o desenvolvimento sustentável.

O território nacional inegavelmente é de grande dimensão e historicamente permeado por desigualdades físicas, políticas, sociais e econômicas, daí, retira-se a imprescindibilidade da intervenção estatal com o escopo de equilibrar e distribuir a riqueza e equalizar as oportunidades, o que é consequência de uma atividade de planejamento bem desenhada, executada e avaliada.

$\mathrm{Na}$ esfera estatal, vislumbra-se que o planejamento ganha um contorno de obrigatoriedade, especialmente em vista do disposto no art. 174 in fine, bem como no art. 165 da Constituição da República Federativa do Brasil, este último permitindo a ilação de que o planejamento se dá também quando da elaboração das leis orçamentárias (plano plurianual, as leis de diretrizes orçamentárias e os orçamentos anuais), contudo, muitas vezes esse 
planejamento realizado pelas leis orçamentárias não é suficiente para fugir das "armadilhas do caixa único", realizados a partir do sistema de "vasos comunicantes", conforme as lições de Scaff $(2014$, p. 321)

Muitas vezes esquecido, em nível infraconstitucional, temos o Decreto-Lei $\mathrm{n}$. 200/67 (BRASIL, 1967), que em seu Art. $6^{\circ}$ elenca o planejamento como um princípio fundamental da Administração Federal, enquanto no Art. $7^{\circ}$ determina que a atividade de planejamento objetive "promover o desenvolvimento econômico-social do País e a segurança nacional, norteando-se segundo planos e programas elaborados", tendo por instrumentos o plano geral de governo; os programas gerais, setoriais e regionais, de duração plurianual; o orçamento-programa anual; e a programação financeira de desembolso. A Lei Complementar n. 101/2000 (BRASIL, 2000) possui o capitulo II todo voltado ao planejamento que se perfaz pelas leis orçamentárias.

Desse modo, para que o país se desenvolva, é imprescindível o planejamento pelo Estado e a conjugação de esforços para a sua concretização, visando possibilitar transformações sociais.

O planejamento é ferramenta essencial no processo de desenvolvimento econômico e social, entretanto, é primordial que haja "(...) convergências políticas, econômicas e conscientização social para sua eficaz implementação" (ADRI, 2010, p. 62).

O planejamento econômico é um dever do Estado que possibilita, com mais eficiência, o progresso econômico e dispensa maior atenção aos problemas sociais decorrentes da inércia estatal frente ao poderio de estreita "oligarquia financeira".

Como requisito para um adequado planejamento, é fundamental que o Estado identifique a estrutura econômica e social do país, a fim de direcionar suas ações aos setores com maior ou menor intensidade, a depender das exigências e finalidades almejadas. De tudo que foi dito, algumas ilações podem ser realizadas do planejamento da atividade econômica, consoantes as lições de Adri (2010, p. 242-247) que conclui que (a) o planejamento estatal é um dever legal e não uma faculdade, e deve contar sempre com a atuação legitimadora e integradora do setor privado; (b) o planejamento estatal visa coordenar recursos orçamentários disponíveis, aplicando-os a metas específicas, no tempo e modo previamente previstos, com o mínimo de custo; (c) a publicidade, transparência e responsabilidade fiscal, aliado a planejamento de médio e longo prazo permitirá o soerguimento econômico e social do modelo de Estado Democrático de Direito; (d) existe nítida imbricação entre as atividades planejadoras e a elaboração das leis orçamentárias; (e) a exposição de motivos da lei que encaminha o respectivo plano estatal, vislumbra-se um instrumento interpretativo na implementação; (f) planejamento é condição sine qua non para um desenvolvimento organizado e sistemático na direção de uma sociedade melhor.

Na busca pelo bem-estar social, é insofismável condicionar a atividade econômica ao planejamento, pois trará segurança jurídica, publicidade, lisura e eficiência ao exercício estatal e, ainda mais, ao setor privado.

Percebe-se que há uma ausência de uma política pública que permita transformar a exploração dos recursos minerais em desenvolvimento econômico, ambiental e social. E não se pode deixar de entender o Estado ator imprescindível na determinação dos resultados econômicos, o que forçosamente nos conduzirá nas discussões à respeito da aplicação dos recursos arrecadados à título de CFEM, especialmente para elidir ou minorar as externalidades negativas da atividade mineraria.

\section{COMPENSAÇÃO FINANCEIRA PELA EXPLORAÇÃO DOS RECURSOS MINERAIS (CFEM)}

\subsection{Marco legal}


Não resta extreme de dúvida que os contornos jurídicos da CFEM devem ser extraídos a partir da CRFB, notadamente do art. 20, IX, c/c $\S 1{ }^{\circ}$. Em nível infraconstitucional, tem-se a edição da Lei n. 7.990, de 28 de dezembro de 1989 (BRASIL, 1989) e posteriormente da Lei n. 8.001, de 13 de março de 1990 (BRASIL).

Esta última alterada recentemente pela Medida Provisória n. 789, de 25 de junho de 2017 (BRASIL, 2017), convertida na Lei n. 13.540, de 18 de dezembro de 2017 (BRASIL, 2017).

Já em nível infralegal pelo Decreto n. 1, de 11 de janeiro de 1991 (BRASIL, 1991) e Decreto n. 3.739, de 31 de janeiro de 2001 (BRASIL, 2001). Ainda, em destaque, dentre outras normas de natureza secundárias, encontra-se a Portaria n. 239/2018.

\subsection{Conceito}

Conceituar algo ou alguma coisa depende certamente da catalogação do objeto, para se extrair todas as nuances desse objeto. Conforme verá, a discussão da natureza jurídica da CFEM é algo infindável na doutrina, o que acaba por refletir num número igualmente de conceitos a partir do referencial adotado. Assim, para efeito de iniciar a discussão, passaremos apenas a transcrição de dois conceitos que não aderem a nenhuma das categorias específicas que estão em disputa, para compreendermos minimamente sobre o que estando falando.

Castro Júnior e Silva (2018, p. 63) entendem que "a CFEM possui natureza de participação no resultado da atividade mineral, o que equivale a dizer participação no resultado da lavra", e complementa este entendimento com a citação de trecho do RE 228.800/DF, quando diz que resultado da lavra "entendido o resultado não como o lucro do explorador, mas como aquilo que resulta da exploração".

Segundo Martins e Tomelin (2014, p. 17) "a CFEM é a compensação criada pela $\mathrm{CF} / 88$ com vistas a possibilitar um caixa financeiro específico para sanar as externalidades negativas advindas da exploração mineral.”.

Por fim, tem-se que segundo a posição jurisprudencial foi no sentido de reforçar o dispositivo constitucional básico que instituiu a sua cobrança, quando Castro Junior e Silva (2018, p. 63) assim propugnaram:

Trata-se de exação cujo espécie foi definida pela própria Constituição como compensação financeira ou participação nos resultados da atividade de mineração (art. 20, $\S 1^{\circ}$ ), conforme juízo de conveniência e oportunidade do legislador. No caso da opção realizada pela Lei n. 7.990/1989 e, posteriormente, pela Lei n. 13.540/2017, como será analisado adiante, a partir da jurisprudência, a CFEM possui natureza jurídica de participação no resultado da atividade mineral, o que equivale dizer participação no resultado da lavra, "entendido o resultado não como o lucro do explorador, mas como aquilo que resulta da exploração" (RE n. 228.800/DF)

Assim, a própria formulação e compreensão do conceito, deve partir da análise da taxionomia jurídica do instituto, tanto que os conceitos acima citados alinham-se ao entendimento da CFEM como royalties pagos pelas empresas mineradoras pela exploração de um bem da União, constituindo-se nas palavras de Scaff (2014, p. 89) em "pagamento pelo custo de oportunidade (user cost) de um recurso exaurível"

\subsection{Natureza jurídica}

Antes de adentrar a natureza jurídica da CFEM, é bom esclarecer que a questão referente à natureza jurídica é controvertida na doutrina, havendo a disputa entre vários ramos 
do direito para abarcar o fenômeno, sendo certo que ao final será exposto o entendimento jurisprudencial, porquanto, como diz o adágio popular o direito não é o que os estudiosos interpretam, mas o que os Tribunais julgam.

Neste particular, é muito importante definir a natureza jurídica da CFEM justamente para submetê-la ao regime jurídico próprio da espécie.

Penso ser importante primeiro catalogar a CFEM como receita originária ou derivada, que nada mais é do que uma discussão propriamente de direito financeiro.

O direito financeiro - mantém íntimas relações com o direito tributário - , cuida da atividade financeira do Estado, que se constitui na atividade de obter (receita pública), despender (despesa pública), criação (crédito ou dívida pública) ou gerir (orçamento público). Dentre as receitas, temos as originárias que decorrem da exploração do patrimônio do Estado, e as receitas derivadas que decorrem da exploração do patrimônio dos particulares, tais como a cobrança de tributos.

Como os recursos advindos da CFEM são decorrentes da exploração dos recursos minerais que são propriedade da União, não resta extreme de dúvidas, estaremos diante das receitas originárias e não derivadas. Daí, afastar a natureza jurídica da CFEM como imposto ou taxa é uma tarefa excessivamente tranquila, porquanto impostos, taxas, contribuições de melhoria são exemplos de espécies tributárias e que, portanto, detém natureza de receita derivada. Martins e Tomelin (2014, p. 21) indicam que:

14. As receitas públicas se dividem em originárias, derivadas e transferidas. As originárias são as patrimoniais diretas, tais como o valor pago pela concessão de um bem ou de um serviço ou pela locação de um próprio público dominial do estado (sic) a terceiro. As derivadas são as que defluem da força estatal de exigir pecúnia $a b$ ovo, das quais o notório exemplo são os ingressos tributários. Já as receitas transferidas consistem naqueles ingressos que são repassáveis de um ente público a outro, seja a guisa de subvenções, seja em função de direita repartição constitucional de receitas (por exemplo, os fundos de participação)

15. Pois bem. É inegável que a CFEM, já à primeira vista, assemelha-se a tributo. Relevante será, porém, saber se se manterá tal impressão inicial a partir do momento em que o intérprete faça abstração do enorme aparato "tributarístico" que a exação teve de aproveitar, como reminiscência dos tempos do Imposto único sobre Minerais (IUM), fiscalizando que era, este, por mecanismos e estrutura administrativa muito semelhante aos atuais, com os quais a CFEM tem que conviver.

Mas ainda assim, a CFEM pode se aproximar na noção de impostos, mas que Silva (2017, p. 61) afastou como extrema facilidade quando assim asseverou:

A CFEM não apresenta natureza jurídica de impostos, pois, apesar de se pautar em fato que ocorre independentemente da atuação estatal, tal como nos impostos, sua exigibilidade apenas ocorre caso exista a exploração mineral, não sendo decorrente do poder de império do Estado. Além disso, como argumenta o Min. Sepúlveda, a simples previsão da CFEM em lei, como prestação pecuniária compulsória, não transforma sua natureza jurídica em tributária. Assim, sua exigibilidade está vinculada ao aproveitamento do bem de titularidade da União.

Permita-me apenas ressaltar que entendo que a aplicação dos recursos advindos da CFEM não seria de natureza não vinculada, quando o trecho acima transcrito indica que os recursos arrecadados independem de atuação estatal específica. A despeito de entendimentos em contrário, advoga-se neste artigo a vinculação dos recursos arrecadados à titulo de CFEM “....para sanar as externalidades negativas advindas da exploração mineral.” (MARTINS E TOMELIN, 2014, p. 17). 
Também não teria a CFEM a natureza de taxa. Bem se sabe que as taxas, como espécie tributária são cobradas em decorrência do poder de polícia, bem como compradas pela prestação de serviços públicos específicos e divisíveis pelo poder público, o que não é o caso.

Por outro lado, a CFEM também não pode ser catalogada como preço público, posto que o preço público decorre da contrapartida a ser paga por particular ao poder público, fundado em regime de direito privado, segundo Silva (2017, p. 61):

Neste sentido, não é possível classificar a CFEM como preço público, já que aquela consiste na remuneração devida em razão de exploração (no sentido de exaurimento e não apenas de uso) de bem público e não prestação pecuniária a fim de pagar serviço público ou remunerar a delegação de determinadas atividades econômicas.

Apenas para citar, posto haver menor repercussão sobre esses pontos de vista, Silva (2010), coordena obra que cataloga outras possibilidades como natureza jurídica da CFEM. O direito administrativo presta a estuda a CFEM ora como indenização administrativa, ou até mesmo como contraprestação pelo uso de bem público. No direito tributário também há estudos que atribuem a natureza jurídica de Contribuição sobre o Domínio Econômico. E por fim, o direito ambiental busca enquadrá-lo como indenização de natureza ambiental.

Entrementes, Silva (2014, internet) asseverá que:

Constituem doutrina e jurisprudência dominantes que a CFEM tem natureza jurídica de uma receita patrimonial. Dessa forma, constitui-se uma relação jurídica de caráter não-tributário, porém fundamentada em obrigação de Direito Administrativo.

E mais adiante Silva (2014, internet) traz a colação um julgado do Tribunal Regional Federal da $4^{\mathrm{a}}$ Região consagrou esse entendimento, afirmando que o prazo prescricional para cobrança de CFEM é de cinco anos, destacando a sua natureza jurídica. Vejamos:

\begin{abstract}
"DIREITO MINERÁRIO. COMPENSAÇÃO FINANCEIRA PELA EXPLORAÇÃO DE RECURSOS MINERAIS. NATUREZA JURÍDICA. PRESCRIÇÃO. DEDUÇÃO DO ICMS. A cobrança de Compensação Financeira pela Exploração de Recursos Minerais (CFEM) é prevista no art. $20, \S 1^{\circ}$, da CRFB, constituindo-se em receita patrimonial da União. Não se trata, portanto, de preço público - contraprestação contratual por prestação de serviço público. Tratando-se de relação jurídica de caráter não-tributário com assento no Direito Administrativo, aplica-se-lhe, por simetria, o prazo prescricional de cinco anos previsto no art. $1^{\circ}$ do Decreto n. $^{\circ}$ 20.910/32."
\end{abstract}

Comungamos do entendimento Lucas (2015, p. 54) que conclui ser receita patrimonial de bem da União, quando assim assevera:

Aderimos, portanto, aos posicionamentos que defendem tratar-se a compensação financeira pela exploração mineral como receita patrimonial originária da União, repartida com os demais entes federados nos quais ocorra essa exploração, como forma de indenização pelos danos causados pela atividade mineradora e pela extinção futura de uma riqueza não renovável. A definição no sentido de que os entes federados devem ser indenizados pela exploração dos recursos minerais em seus territórios é importante para que possamos discutir qual a adequada destinação dessas receitas, a fim de se mitigar os feitos dos danos causados pela atividade mineradora presente em milhares de municípios brasileiros e preparar a sociedade local para o desenvolvimento com prevenção pelo fim da exploração dos minérios.

Por fim, calha destacar a observação de Lott $(2019$, p. 72$)$ quando asseverou: 
A Compensação Financeira pela Exploração Mineral - CFEM, como instrumento econômico encontrado no Brasil como vistas a remunerar as regiões e entres públicos pelo minério extraído, tem como desafio, entre outros, possibilitar ao municípios a sustentabilidade do seu desenvolvimento pela renda auferida com a mineração.

E neste contexto, denota-se a importância da atividade de planejamento para a aplicação dos referidos recursos, seja para debelar as externalidades negativas, principalmente no que pertine ao meio ambiente, seja garantir melhor qualidade de vida, com reflexos nos índices de desenvolvimento humano, ou permitir sustentabilidade econômica e social, com a realização de projetos que garantam a utilização de mão-de-obra excedente, quando ocorre a diminuição da atividade de extração mineral por exaustão ou por questões mercadológicas, dentre outras.

\subsection{Destinação subjetiva}

A CFEM é calculada sobre o valor do faturamento líquido (receita da comercialização menos custos e tributos) obtido por ocasião da venda do produto mineral. Com efeito, as alíquotas aplicadas sobre o faturamento líquido para obtenção do valor da CFEM, variam de acordo com a substância mineral e são pagas mensalmente. Até a edição da Medida Provisória n. 789, de 25 de junho de 2017 (BRASIL, 2017), convertida na Lei n. 13.540, de 18 de dezembro de 2017 (BRASIL, 2017), os valores devidos eram calculados segundo o quadro baixo:

Quadro 1: Percentuais de distribuição da CFEM antes da MP 789/2017

\begin{tabular}{|c|l|}
\hline Alíquota & \multicolumn{1}{|c|}{ Substância } \\
\hline $3 \%$ & $\begin{array}{l}\text { minério de alumínio, manganês, sal- } \\
\text { gema e potássio }\end{array}$ \\
\hline $2 \%$ & $\begin{array}{l}\text { ferro, fertilizante, carvão, demais } \\
\text { substâncias }\end{array}$ \\
\hline $1 \%$ & ouro \\
\hline $0,2 \%$ & $\begin{array}{l}\text { pedras preciosas, pedras coradas } \\
\text { lapidáveis, carbonetos e metais nobres }\end{array}$ \\
\hline
\end{tabular}

Fonte: ANM

(https://sistemas.dnpm.gov.br/Arrecadacao/extra/Relatorios/arrecadacao_cfem.aspx)

Após edição da MP acima referida, o anexo da Lei n. 8.001, de 13 de março de 1990, passou a vigorar com a seguinte redação:

Quadro 1: Percentuais de distribuição da CFEM antes da MP 789/2017

\begin{tabular}{|c|c|}
\hline ALOUOTA & SUBSTLVOA MUERLL \\
\hline (vGTapQ) & (NETADO) \\
\hline 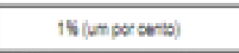 & 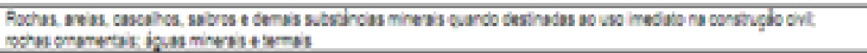 \\
\hline 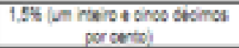 & 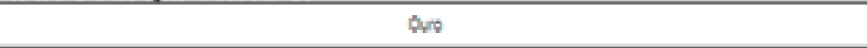 \\
\hline 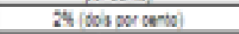 & 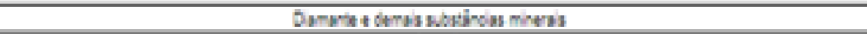 \\
\hline Whits arots) & 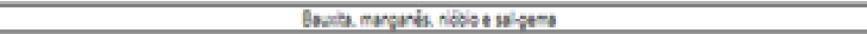 \\
\hline 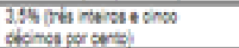 & 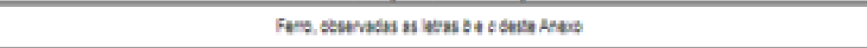 \\
\hline
\end{tabular}

Fonte: Anexo da Lei n. 13.540 (BRASIL, 2017)

Conforme já mencionado, os valores arrecadados a título de CFEM são repartidos entre a União, bem como o Estado e Município que se deu a exploração mineral, conforme percentual previsto em legislação específica. 
Recentemente estes percentuais foram alterados pela Medida Provisória n. 789, de 25 de junho de 2017 (BRASIL, 2017), convertida na Lei n. 13.540, de 18 de dezembro de 2017 (BRASIL, 2017)

A divisão era assim realizada: $65 \%$ para o município onde ocorria a extração; $23 \%$ para o Estado de origem da extração e $12 \%$ para União, divididos por sua vez em $9,8 \%$ ao DNPM; 0,2 ao IBAMA e $2 \%$ para o Ministério de Ciência e Tecnologia, mais especificamente para o Fundo Nacional de Desenvolvimento Científico e Tecnológico.

Agora, o art. $2^{\circ}, \S 2^{\circ}$ da Lei n. 8.001, de 13 de março de 1990, passou a vigorar com a seguinte redação:

$\S 2^{\mathrm{o}}$ A distribuição da compensação financeira referida no caput deste artigo será feita de acordo com os seguintes percentuais e critérios:

I - 7\% (sete por cento) para a entidade reguladora do setor de mineração;

II - $1 \%$ (um por cento) para o Fundo Nacional de Desenvolvimento Científico e Tecnológico (FNDCT), instituído pelo Decreto-Lei no 719, de 31 de julho de 1969, e restabelecido pela Lei $\mathrm{n} \times 8.172$, de 18 de janeiro de 1991, destinado ao desenvolvimento científico e tecnológico do setor mineral;

II-A (revogado);

III - 1,8\% (um inteiro e oito décimos por cento) para o Centro de Tecnologia Mineral (Cetem), vinculado ao Ministério da Ciência, Tecnologia, Inovações e Comunicações, criado pela Lei $\mathrm{n}^{\mathrm{0}} \mathbf{7 . 6 7 7}$, de 21 de outubro de 1988, para a realização de pesquisas, estudos e projetos de tratamento, beneficiamento e industrialização de bens minerais; IV - 0,2\% (dois décimos por cento) para o Instituto Brasileiro do Meio Ambiente e dos Recursos Naturais Renováveis (Ibama), para atividades de proteção ambiental em regiões impactadas pela mineração;

V - 15\% (quinze por cento) para o Distrito Federal e os Estados onde ocorrer a produção;

VI - 60\% (sessenta por cento) para o Distrito Federal e os Municípios onde ocorrer a produção;

VII - 15\% (quinze por cento) para o Distrito Federal e os Municípios, quando afetados pela atividade de mineração e a produção não ocorrer em seus territórios, nas seguintes situações:

a) cortados pelas infraestruturas utilizadas para o transporte ferroviário ou dutoviário de substâncias minerais;

b) afetados pelas operações portuárias e de embarque e desembarque de substâncias minerais;

c) onde se localizem as pilhas de estéril, as barragens de rejeitos e as instalações de beneficiamento de substâncias minerais, bem como as demais instalações previstas no plano de aproveitamento econômico; e

d) (VETADO)

Percebe-se, portanto, que a Lei não apenas estabeleceu novos percentuais para a distribuição de CFEM aos entes da federação, bem como incluiu um novo critério, qual seja, que será devida à municípios afetados pela atividade de mineração, quando a produção não ocorrer em seus territórios.

A situação é nova, tanto que recentemente a ANM, lançou o edital de Consulta Pública n. 1/2019 (BRASIL, 2019) convocando os municípios que se sintam afetados com a atividade minerária a postular a partir de critérios técnicos participação no resultado da arrecadação da CFEM, tudo nos termos da NOTA TÉCNICA No 001-GAEM/SPM/ANM (BRASIL, 2019).

Calha destacar também que diante da inevitável exaustão dos recursos minerais não renováveis, o poder público deveria cuidar da forma de aplicação dos recursos da CFEM, porquanto este constitui a sua principal fonte de arrecadação com a atividade minerária.

Importante destacar que o art. $8^{\circ}$, caput, e $\S \S 1^{\circ}$ e $2^{\circ}$ da Lei n. 7.990 (BRASIL, 1989), proíbe que entes federados apliquem os recursos da CFEM no pagamento de dívida e 
despesas com quadro permanente de pessoal, excluídas as dívidas da União e suas entidades, o custeio do ensino e a capitalização dos fundos de previdência.

Assim, essa vedação cai no vazio, porquanto é negativa, ou melhor, a legislação não é clara em dizer onde deve ser aplicado, mas ao contrário, realiza uma vedação inócua, posto como bem asseverou Scaff $(2014$, p. 320) a proibição é facilmente burlada em vista dos "vasos comunicantes orçamentários", quando asseverou que:

Ocorre que no atual estágio do federalismo fiscal brasileiro, estabelecer esse tipo de vedações, inclusive com as exceções mencionadas [dívidas com a União e suas entidades, custeio do ensino e a capitalização dos fundos de previdência], possui pouquíssima eficácia, em razão de amplo sistema de vasos comunicantes orçamentários, na linha da liberdade de conformação do legislador orçamentário, que permite a alocação de verbas de acordo com o interesse público dos órgãos responsáveis pela construção do orçamento do país. A verba que não pode ser usada para realizar o gasto $X$ é carreada para o $\mathrm{Y}$, permitindo que outra verba seja usada para fazer frente àquela despesa. Assim, a vedação ao uso dos royalties para o pagamento de despesas com pessoal faz com que esse dinheiro possa ser utilizado em outras despesas que seriam necessariamente custeadas com os recursos que foram destinados a essas despesas com pessoal.

O importante, para além da discussão do aumento da base de cálculo, alíquotas ou até mesmo o percentual de distribuição entre os entes federados dos recursos arrecadados à titulo de CFEM, tem-se que assegurar sua aplicação em promover o desenvolvimento sustentável é que será a grande chave para realização da finalidade de sua criação e garantir a realização do direito fundamental à boa administração pública.

\section{SUSTENTABILIDADE SOCIAL, ECONÔMICA E AMBIENTAL DOS EMPREENDIMENTOS QUE EXPLORAM A ATIVIDADE MINERÁRIA}

A sustentabilidade socioecnômica e ambiental é um imposição constitucional e legal, mas antes de tudo ética. Entrementes, os empreendimentos minerários antes de mais nada deverão ostentar viabilidade econômica, sem a qual não se chega sequer a cogitar da viabilidade social e ambiental.

A partir de uma atividade de planejamento econômico, com estudo exaustivo plano de negócio é que se verificará a viabilidade econômica do empreendimento, devendo o licenciamento ambiental, acompanhado da formulação de políticas públicas de cunho social e econômico, impor condicionantes à concessão de licenças de lavra. Tem-se, neste contexto, a aplicação dos recursos arrecadados a título de CFEM, ou eventual receita que venha a substituí-la, devem encarados como ferramenta para se alcançar a sustentabilidade na mineração (LOTT, 2019).

Assim, muito antes de discutir o aumento da base de cálculo da CFEM e a majoração de sua alíquota, ou até mesmo percentual de distribuição desses recursos entre as entidades estatais, é necessários analisar a atividade de planejamento, aplicação e controle dos recursos arrecadadas, sendo importante saber qual a destinação dada pelos entes públicos para essa receita arrecadada e qual o grau de transparência na gestão. Neste particular, destaca-se as lições de SILVA (2017, p. 59):

Pode-se dizer que os royalties constituem-se como pagamento pelo custo de oportunidade (user cost) de um recurso exaurível. Por ser um recurso não renovável, sua exploração implica esgotamento futuro, impõe um custo de oportunidade que precisa ser remunerador. 
O certo é que inevitavelmente haverá a interrupção definitiva ou temporária da atividade mineraria em determinado local, seja no primeiro caso pela exaustão, seja por interferência mercadológicas ou tecnológicas que demandariam a paralisação temporária.

E mais certo ainda é que a atividade mineraria apresenta consequências econômicas, sociais e ambientais que devem ser enfrentadas a partir de um planejamento prévio de uma política pública estrutural do Estado brasileiro, que preveja a adequada aplicação e controle dos recursos arrecadados a titulo de CFEM, inclusive, com a constante avaliação e redefinição da política pública setorial.

A interrupção da atividade mineraria pode comprometer nas receitas locais e regionais sensivelmente. A atividade de planejamento dessa atividade econômica, deve prever as intercorrências negativas da paralisação da atividade mineraria, seja pela exaustão dos recursos minerais, ou ocasionados pela temporária baixa da cotação internacional (comodites). Assim, a correta aplicação dos recursos arrecadados a título de CFEM poderiam debelar os efeitos nefastos em cada uma das áreas já indicadas, ocasionando o desenvolvimento sustentável. Daí as lições de Poveda (2007, p. 10) quando assevera que:

O planejamento e controle operacional em mineração são fundamentais para o pleno
exercício da atividade da indústria mineral, o desenvolvimento sustentável deste
setor depende o bom senso, da boa administração e do respeito aos princípios
fundamentais que norteiam o direito minerário. Em contrapartida como o bem
mineral existente em uma determinada jazida não é infinito, tampouco renovável,
desde o início das atividades extrativas, é possível planejar a vida útil do
empreendimento minerário, sendo o único seguimento que pode prever o seu
fechamento e a sua desativação em razão da exaustão do bem mineral ou sua
possível inviabilidade quer sob aspecto técnico ou econômico.

No âmbito econômico, o poder público com o incremento da arrecadação dos valores da CFEM deve buscar alternativas para o arranjo produtivo local e regional. Assim, deverá amealhar com a iniciativa privada alternativas de negócio para dar sustentáculo à toda cadeia produtiva criada em função da atividade minerário, ou proporcionar ambiente empresarial propicio para instalação de novos empreendimentos ou alteração das finalidades institucionais dos já existentes, para não haver solução de continuidade do desenvolvimento local, mantendo os índices econômicos como a renda per capta.

A criação de outros pólos econômicos, para além do minerário é uma solução para alcançar o desenvolvimento sustentável no âmbito econômico, inclusive, preparando para as intercorrências mercadológicas e a própria exaustão dos recursos.

Já no âmbito ambiental deve haver um cuidado todo especial quanto ao necessário licenciamento ambiental e acompanhamento do cumprimento das condicionantes. Deve-se buscar a recuperação da área degradada, especialmente com os devidos cuidados com a desativação dos empreendimentos minerários. Amado (2018, p. 455) mencionado o art. $1^{\circ}$ do Decreto n. 97.632/1989, indica que "os empreendimentos que se destinam à exploração de recursos minerais deverão, quando da apresentação do estudo de impacto ambiental" (BRASIL, 1989).

Atualmente, o Brasil foi assolado por dois grandes acidentes com o rompimento das barragens de Mariana e Brumadinho, ambos em Minas Gerais, com graves consequiências econômicas, ambientais e sociais. Tais ocorrências chamam a atenção para a responsabilidade do Estado e das empresas mineradoras para o fechamento de mina e destino dos rejeitos.

Por fim, na seara social, tem-se que os empreendimentos minerários ostentam "o mais elevado índice de mortalidade e incapacidades permanentes", segundo Barreto (2001, p.189), apesar de pouco contribuir em números absolutos com os empregos formais.

Por outro lado, sabe-se que o percentual da mão de obra ativa na atividade mineraria é baixo, mas se trata de uma mão de obra excessivamente especializada, o que 
denota a necessidade de capacitação dessa mão de obra para outras atividades do setor produtivo, notadamente quando da paralisação da atividade, sob pena de formação de um contingente de desempregados.

Com efeito, os recursos distribuídos a partir do recolhimento da CFEM já têm uma destinação bem específica, a despeito de não existir uma obrigação legal para o emprego direto e imediato para garantir a sustentabilidade econômica, social e ambiental dos empreendimentos minerários.

\subsection{A questão orçamentária}

Após a promulgação da Constituição da República Federativa do Brasil, o planejamento se realizou basicamente pela edição das leis orçamentárias, quais sejam: Plano Plurianual (PPA); Lei de Diretrizes Orçamentárias (LDO) e Lei Orçamentária Anual (LOA). Pinheiro (2015, p. 69) enaltece que:

Portanto, verifica-se o maior zelo do legislador constituinte em disciplinar o relacionamento entre os instrumentos de planejamento, representados pelo PPA, pela LDO e pela LOA, cada qual com suas funções específicas. É importante frisar que existem outros instrumentos de planejamento previstos expressamente na Constituição Federal de 1988, tais como: plano nacional de reforma agrária (art. 188), plano nacional de educação (Art. 214), plano nacional de cultura (art. 215, § $\left.3^{\circ}\right)$

Entretanto, esse planejamento realizado exclusivamente pelas leis orçamentárias não se demonstrou satisfatório, notadamente em vista da natureza apenas autorizativa das peças orçamentárias, o que fez com que a Câmara dos Deputados acenasse positivamente para alteração constitucional quanto à aprovação a orçamento impositivo, pelo menos para as emendas parlamentares.

Mas antes da discussão de que o próprio orçamento (e as respectivas emendas) tivesse natureza imperativa e não apenas autorizativa, tem-se que destacar a necessidade de assegurar que determinadas matérias constem de maneira obrigatória nas peças orçamentárias, diminuindo o grau de discricionariedade no planejamento estatal.

O que se tem, via de regra, é que os recursos recebidos pelas entidades estatais à título de CFEM são "engolidos" pelas necessidades imediatas e ilimitadas que todos municípios apresentam (ENRIQUEZ, 2008, p. 360).

Silva (2017, p. 75) indica que:

A 'armadilha do caixa único' faz com que os gestores públicos percam a potencialidade transformadora das compensações financeiras para diversificação produtiva, geração de emprego e renda, redução da pobreza e promoção de desenvolvimento.

E mais adiante acrescenta Silva (2017, p. 75):

A 'armadilha do caixa único' promove ainda outro efeito nefasto, na medida em que pode acentuar a guerra fiscal entre os entes federados. É que a liberdade decorrente da manipulação dos 'vasos comunicantes' aumenta a margem para a renúncia de receita própria, na medida em que os recursos decorrentes da CFEM serão utilizados para arcar com as despesas decorrentes outrora honrados com outros impostos, objeto da renúncia fiscal.

Percebe-se, portanto, que a aplicação dos recursos recebidos à título de CFEM exclusivamente pela via das leis orçamentárias (PPA, LDO e LOA) se revela ineficiente em vista das diversas mazelas acima apontadas, além de não garantir a aplicação dos valores a partir da razão pela qual foi criada à CFEM. 


\subsection{A necessidade de criação de fundos próprios para a realização do direito fundamental à boa administração}

Nossa proposta é a criação de fundos próprios, com clareza de destinação para promover o cumprimento da função social da propriedade minerária, tanto no aspecto econômico, social e ambiental.

Frisa-se, que a aplicação desses recursos serviria para debelar ou minorar os efeitos das externalidades negativas quando da exaustão dos recursos minerários, ou aqueles advindos pela própria exploração, tais como os invitáveis danos ambientais, ou ainda quando das variações próprias da exploração da comodites, com variações de preços e demanda de tal ou qual minério - o que pode refletir na ociosidade da mão-de-obra, bem como no arrefecimento do comércio das localidades atingidas.

A criação dos respectivos fundos, poderia se embasar nas experiências de alguns municípios mineiros, adotado por exemplo o modelo do "Fundo de Desenvolvimento Econômico e Social de Itabira", criado em 1992, na cidade mineira, com o objetivo de promover a diversificação da atividade econômica, conjugando com outras experiências, tais como na Colômbia, com o "Fundo Nacional de Regalias", destinado à promoção da mineração, preservação do meio ambiente e realização de projetos regionais definidos como prioritários.

Neste particular, é bom destacar que Constituição Mineira determina a criação desses fundos ( $\S 3^{\circ}$ do art. 253), não encontrado, por exemplo, disposição correspondente dentre os artigos que tratam de atividade de mineração na Constituição Goiana (v. arts. 140 e 141), o que ao nosso sentir não representa um obstáculo para que o Estado de Goiás também adote esta orientação, porquanto é o terceiro em recolhimento de CFEM, ficando atrás apenas dos Estados de Minas Gerais e Pará (Dados do portal da ANM).

Lucas (2015, p. 101) vaticina que:

Com efeito, dentre essas ações calcadas no planejamento local defendemos a criação de fundos públicos de destinação, como reservas de recursos a serem movimentas futura e excepcionalmente em momentos de recessão econômica da atividade mineradora, e, sobretudo, aplicadas em setores e atividades econômicas substitutivas da exploração mineral, a fim que se assegure o Direito ao Desenvolvimento Local, na expressão de CLARK (2001).

E mais adiante Lucas (2015, p. 101) explicita que:

$\mathrm{O}$ fundo público, enquanto um dos possíveis desdobramentos do planejamento possibilita ainda um comprometimento e um debate na comunidade impactada pela atividade mineradora, sobre as ações públicas necessárias para a destinação da CFEM como medida compensadora pela sobrecarga dos aparelhos públicos, conforme vimos nos casos estudados nessa obra, envolvendo os municípios de Parauapebas, Nova Lima, Itabira e Itatiaiuçu.

Nosso posicionamento encontra amparo também no Tribunal de Contas do Estado de Minas Gerais, que, em auditoria realizada nos municípios de Nova Lima e Itabira, identificou a ausência de "Fundo gestor dos recursos com plano de ação definido", como uma das causas prováveis para a malversação dos recursos da CFEM.

Assim, nada mais justo do que para além do direito econômico ao desenvolvimento, deve-se prezar pelo direito ao desenvolvimento na acepção de dizer respeito aos "direitos sociais e culturais de coletividades atingidas pelos impactos negativos das externalidades econômicas, quando pugna pela proteção ambiental em benefício da espécie humana ou quando atua na luta pela inclusão social dos povos do planeta" (FEITOSA, 2013, p. 14). 
Não se trata aqui de buscar alterar o regime jurídico da cobrança e aplicação dos recursos da CFEM nos moldes internacionais, tal como proposto por SILVA (2017), quando discute a incidência dos royalties no cenário internacional, mais especificamente da Austrália Ocidental, realizando verdadeiro transplante jurídico criticado por Legarnd (ano), mas de aplicar a experiência havida internamente, como em Itabuna, com a criação de um fundo específico visando à aplicação dos recursos arrecadas a título de CFEM, para elidir ou minorar as externalidades negativas da atividade mineraria, em especial.

A CFEM como uma ferramenta para alcançar a sustentabilidade na mineração, mas que para tanto deve ter seus contornos bem definidos juridicamente, apreciando as questões para além das discussões sobre natureza jurídica, mas sim para permitir uma harmonização da questão minerária, com relação às questões ambientais, sociais e econômicas que surge a partir da opção de se explorar um recurso minerário.

Daí a importância do planejamento, que esteja envolvido com questões éticas, para além das questões econômicas, para preservar o meio ambiente, resguardar a mão de obra empregada na atividade minerária após a exaustão do recurso ou paralisação das atividades, bem como possibilitar a realização de outros investimentos econômicos alternativos à atividade minerária, que permitam a sustentabilidade econômica da comunidade atingida pela atividade da mineração.

Freitas (2014, p. 171), ao destacar a atuação indireta e regulatória do Estado, enfatiza a necessidade de fazer com que os agentes de mercado e do governo cooperem para o desenvolvimento sustentável, via exercício legal e legítimo, prevenido e precavido, normativo e concreto, ampliando a inteligência do poder de polícia administrativo, além de exigir qualidade dos bens e serviços em conformidade com a coexistência harmônica dos direitos fundamentais das gerações presentes e futuras.

Assim, a criação de fundos específicos para receber todos os recursos recebidos à título de CFEM e sua utilização vinculada às suas finalidade afastará o atual estágio de absoluta discricionariedade no gasto das referidas verbas - resquícios do patrimonialismo para a realização do direito fundamental à boa administração.

Muñoz (2012, p. 17) sintetiza a intencionalidade do que se entenderia por um bom governo e boa administração:

O bom governo e a boa administração dos tempos em que vivemos há de estar comprometidos radicalmente com a melhora das condições de vida das pessoas, devem estar orientados a fomentar a liberdade solidária dos cidadãos. Para isso, é preciso que o governo e a administração trabalhem sobre os problemas reais do povo e procurem buscar as soluções escutando os setores atingidos.

Encerrando, nota-se que Freitas (2014, p. 172-173) conclui que:

Cumpre, em última análise, assimilar, para todos os efeitos, a boa administração como direito fundamental. Trata-se de relevante mudança de postura, que favorece o desenvolvimento sustentável, aquele que importa. Quer-se, pois a Administração Pública que não se contenta em tornar boas as más escolhas. A partir de agora, com metas pactuadas, confiáveis e sem utopismo ingênuo, imprescindível praticar uma renovada governança pública, com acessa imaginação e verdadeiro compromisso com a sorte das gerações presentes e futuras.

Em relação à administração pública gerencial, não há espaço para amadorismo e o poder público deve profissionalizar seus quadros de servidores, fortalecer suas estruturas de planejamento e buscar uma intensa interação com a iniciativa privada e com a academia, a fim de encontrar soluções para os novos problemas, permitindo um desenvolvimento nacional, com justiça social, visando assegurar a dignidade da pessoa humana. 


\section{CONCLUSÃO}

A atividade mineraria é uma atividade imprescindível para o desenvolvimento da sociedade, mas para além da viabilidade econômica do empreendimento não se deve olvidar do desenvolvimento social e ambiental. Assim, o único desenvolvimento possível tanto sob o aspecto jurídico, quanto pelo aspecto ético é o desenvolvimento sustentável.

Contudo, as externalidades negativas da atividade mineraria devem ser debeladas a partir da aplicação adequado do recursos recebidos por cada entidade federativa à título de CFEM. Aliás, a CFEM foi criada justamente com essa função, qual seja, promover o desenvolvimento sustentável da região em que há a mineração, inclusive com o planejamento de outras alternativas produtivas, realocação da mão de obra e preservação do meio ambiente, quando da exaustão ou paralisação da atividade mineraria.

$\mathrm{O}$ presente artigo utilizou-se do método dialético que possibilita às bases para interpretar o sentido dinâmico e totalizante da realidade social e buscou justamente demonstrar, para além da utilização das leis orçamentárias como instrumento de planejamento, a criação de fundos específicos para recebimento de todos os recursos recebidos pela entidade federativa a título de CFEM, com a aplicação vinculada as razões de sua instituição.

Assim, seria assegurada a aplicação dos recursos na finalidade para qual foi criado, no que cada entes públicos teria condições de imprimir maior eficiência e um ganho exponencial no grau de transparência na gestão de tais recursos, caminhando rumo a realização do direito fundamental à boa administração.

Por fim, destaca-se a possibilidade de análise da temática por outros ângulos, o que não elide a reconfiguração de um novo marco civilizatório no que pertine a exploração das riquezas minerais (aspecto econômico), com a compatibilização como as demais perspectivas, notadamente a ambiental e social.

\section{REFERÊNCIAS}

ADRI, Renata Porto. O planejamento da atividade econômica como dever do Estado. Belo Horizonte: Fórum, 2010.

BARRETO, Maria Laura. Mineração e desenvolvimento sustentável: desafios para o Brasil. Rio de Janeiro: CETEM/MCT, 2001.

BRASIL. Constituição da República Federativa do Brasil, promulgada em 05 de outubro de 1988. Diário Oficial da União. Brasília de 05 out. 1988.

. Decreto-Lei n. 200, de 25 de fevereiro de 1967. Dispõe sobre a organização da Administração Federal, estabelece diretrizes para a Reforma Administrativa e dá outras providências. Diário Oficial da União. Brasília de 25 fev. 1967.

Lei Complementar n. 101, de 4 de maio de 2000. Estabelece normas de finanças públicas voltadas para a responsabilidade na gestão fiscal e dá outras providências. Diário Oficial da União. Brasília de 4 mai. 2000. 
. Lei n. 13.540, de 18 de dezembro de 2017. Altera as Leis nos 7.990 , de 28 de dezembro de 1989, e 8.001, de 13 de março de 1990, para dispor sobre a Compensação Financeira pela Exploração de Recursos Minerais (CFEM). Diário Oficial da União. Brasília de 18 dez. 2017.

. Lei n. 7.990, de 28 de dezembro de 1989. Institui, para os Estados, Distrito Federal e Municípios, compensação financeira pelo resultado da exploração de petróleo ou gás natural, de recursos hídricos para fins de geração de energia elétrica, de recursos minerais em seus respectivos territórios, plataformas continental, mar territorial ou zona econômica exclusiva, e dá outras providências. (Art. 21, XIX da CF) Diário Oficial da União. Brasília de 28 dez. 1989.

. Lei n. 8.001, de 13 de março de 1990. Define os percentuais da distribuição da compensação financeira de que trata a Lei n ${ }^{\circ} 7.990$, de 28 de dezembro de 1989, e dá outras providências. Diário Oficial da União. Brasília de 13 mar. 1990.

. Medida Provisória n. 789, de 25 de julho de 2017. Altera a Lei no 7.990, de 28 de dezembro de 1989, e a Lei no 8.001, de 13 de março de 1990, para dispor sobre a Compensação Financeira pela Exploração de Recursos Minerais. Diário Oficial da União. Brasília de 25 jul. 2017.

. Portaria/DNPM n. 239, de 23 de março de 2018. Dispõe sobre o $§ 10$ do art. $2^{\circ}$ da Lei $\mathrm{n}^{\circ} 8.001$, de 13 de março de 1990, e sobre o Decreto ${ }^{\circ} 9.252$, de 28 de dezembro de 2017. Diário Oficial da União. Brasília de 23 mar. 2018.

Decreto n. 1, de 11 de janeiro de 1991. Regulamenta o pagamento da compensação financeira instituída pela Lei no 7.990, de 28 de dezembro de 1989, e dá outras providências. Diário Oficial da União. Brasília de 11 jan. 1991.

. Decreto n. 3.739, de 31 de janeiro de 2001. Dispõe sobre o cálculo da tarifa atualizada de referência para compensação financeira pela utilização de recursos hídricos, de que trata a Lei no 7.990, de 28 de dezembro de 1989, e da contribuição de reservatórios de montante para a geração de energia hidrelétrica, de que trata a Lei n⿳0 8.001, de 13 de março de 1990, e dá outras providências. Diário Oficial da União. Brasília de 31 jan. 2001.

. ANM. NOTA TÉCNICA No 001-GAEM/SPM/ANM. Lei n ${ }^{\circ} 13.540 / 2017$ e

Decreto n ${ }^{\circ}$ 9.407/2018 - Regulamentação da apuração e distribuição do percentual de quinze por cento, a título de Compensação Financeira pela Exploração de Recursos Minerais CFEM, para cada substância mineral, entre o Distrito Federal e os Municípios afetados pela atividade de mineração e os Municípios gravemente afetados pela perda de receita da CFEM com a edição da Lei $n^{\circ} 13.540$, de 18 de dezembro de 2017 da CFEM. Diário Oficial da União. Brasília de . 2017.

fev. 2019.

ANM. Consulta Pública n. 1/2019. Diário Oficial da União. Brasília de 25

CASTRO JÚNIOR, Paulo Honório. SILVA, Tiago de Mattos. Compensação Financeira pela Exploração Mineral (CFEM). Belo Horizonte: D'Placido, 2018.

ENRIQUEZ, Maria Amélia Rodrigues da Silva. Maldição ou dádiva? Os dilemas do desenvolvimento sustentável a partir de uma base mineira. Tese de Doutorado. 2007. Centro de Desenvolvimento Sustentável, Universidade de Brasília, Brasília, 2007.

FEITOSA, Maria Luiza de Alencar Mayer. Direito econômico do desenvolvimento e direito humano ao desenvolvimento. Limites e confrontações. In FEITOSA, M.L.A.M.; FRANCO, F.C.O.; PETERKE, S.; VENTURA, V.A.M.F. Direitos humanos de solidariedade: avanços e impasses, p. 171-240.Curitiba: Appris, 2013.

FREITAS, Juarez. Direito fundamental à boa administração pública. $3^{\text {a }}$ edição. São Paulo: Malheiros, 2014. 
LUCAS, Rodrigo de Castro. Compensação Financeira pela Exploração Mineral (CFEM): natureza jurídica e destinação. Belo Horizonte: Arraes Editores, 2015.

LOTT, Denes Martins da Costa. O fechamento de mina e a utilização da contribuição financeira por exploração mineral. Belo Horizonte: Del Rey Editora, 2019.

MARTINS, José Antônio de Andrade. TOMELIN, Georghio Alessandro. Regime jurídico da Compensação Financeira sobre Exploração Mineral (CFEM). Belo Horizonte: Fórum, 2014.

MUÑOZ, Jaime Rodriguez-Arana. Direito fundamental à boa administração pública.Belo Horizonte: Fórum, 2012.

POVEDA, Eliane Pereira Rodrigues. A eficácia legal na desativação de empreendimentos minerários. São Paulo: Signus, 2007.

SCAFF, Fernando Facury. Rotalties do petróleo, minério e energia: aspectos constitucionais, financeiros e tributários. São Paulo: Revista dos Tribunais, 2014.

SILVA, Fernanda Alen Gonçalves da. Recurso minerais: como romper com essa maldição? Belo Horizonte: Arraes Editores, 2017.

SILVA. Tiago de Mattos. A compensação financeira por exploração mineral: prescrição qüinqüenal em função de sua natureza jurídica. Disponível em: $<$ https://ibdm.com.br/a-compensacao-financeira-por-exploracao-mineral/>. Publicado em 13 de maio de 2014. 